\title{
Research on Contact Pressure Distribution of Pad
}

\author{
Dong Chen, Guofeng Zou \\ School of Mechanical and Automotive Engineering, South China University of Technology, Wushan Road No.381, Guangzhou, P.R.China.
}

\begin{abstract}
A simplified thermo-structural coupling finite element model of disc brake was developed. The contact pressure distribution of new pad was simulated under an emergency braking condition. The result shows that the contact pressure distribution of pad is not uniform when the new pad is in normal working condition. The inhomogeneity of the contact pressure is a critical cause of tangential partial wear. Compared the contact pressure distribution of new pad, uniform wear pad and tangential partial wear pad, the influence of wear amount and tangential partial wear on the contact pressure of pad was investigated. The results prove that the influence of wear amount on the contact pressure of pad is very small, while tangential partial wear has a great influence on the contact pressure of pad. The wear and force characteristics of pad are analyzed. The wear of its life cycle of pad is obtained, and the reliability and accuracy of the simulation are verified.
\end{abstract}

\section{Introduction}

Disc brakes are the most common type of brakes on a car. When braking, the pads firmly hold the disc under the braking force, and the vehicle is decelerated or even stopped by the friction between them. During braking, brake disc and pad are elastic deformed, coupled with the friction, so that the contact pressure distribution is uneven between them. It is likely to cause partial wear pad, braking vibration, braking noise, then seriously affect the braking performance of disc brake. Therefore, the study of brake contact pressure distribution on friction interface is an indispensable part in the design and manufacture of brake.

In recent years, domestic and foreign scholars conducted a large number of detailed researches [1], [2]. Huang et al. [3] proposed a contact pressure distribution model of a disc brake that has a variable effect of moving heat source, the elastic deformation of the brake disc and pad, and the frictional heat flux of the interface. Zhang et al. [4] established a three-dimensional transient thermomechanical coupled finite element model, then calculated and analyzed the contact pressure of the brake disc-pad and the thermo-mechanical coupling characteristic of the brake pad under emergency braking conditions. Anders Söderberg et al. [5] conducted a simulation analysis of the wear and contact stress distribution of pad. Gao et al. [6] studied the variation of the contact pressure distribution characteristics of disc brakes under different working conditions by numerical method. Bakar RA et al. [7] obtained the static contact pressure distribution through the pressure indicating film, and obtained the brake contact pressure distribution by establishing the finite element model of disc brake, and studied the influence of the friction surface morphology on the brake contact pressure distribution.

The uneven contact pressure distribution on the frictional interface is the consensus of the above studies, but they rarely involve the contact pressure distribution of the wear and partial wear pads. In this paper, the contact pressure distribution of new pad under emergency braking condition is firstly simulated and analyzed. The contact pressure distribution of wear pad and partial wear pad are then analyzed. The differences between them were compared and the influence of wear amount and partial wear on the contact pressure of pad was investigated. Finally, the wear and force characteristics of pad are analyzed. The wear of life cycle of pad is obtained, and the reliability and accuracy of the simulation are verified. This creative method provides a completely new idea for the study of partial wear of pad. It has certain reference value for the future research of brake design, optimization and vibration noise.

\section{Thermo-Structure Coupling Model of Disc Brake}

\subsection{Disc Brake}

A disc brake model is shown in Fig.1, including brake disc, pads, brake caliper, carrier, piston and other components. The brake disc has a thickness of $26 \mathrm{~mm}$ and a diameter of $281 \mathrm{~mm}$. There are a total of 36 ventilation slots in the circumferential direction of brake disc. A pair of pads is divided into the inner pad (near the piston side) and the outer pad (near the caliper finger side). It has a thickness of $19 \mathrm{~mm}$, a wrap angle of $60^{\circ}$, 
an outer diameter of $140 \mathrm{~mm}$ and an inner diameter of $100 \mathrm{~mm}$.

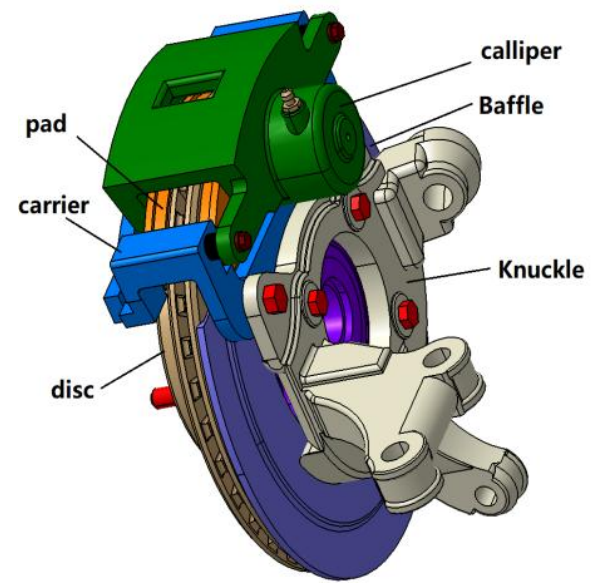

Figure 1. The structure of disc brake.
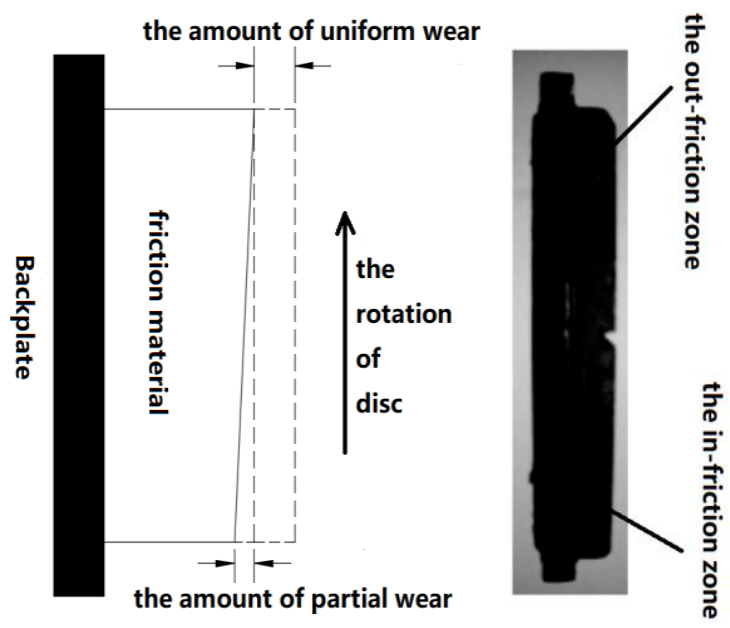

Figure 2. Tangential partial wear design.

It has been described above that the thickness of new pad is $19 \mathrm{~mm}$, whereas the wear pad discussed in this paper is a pad with a uniform wear amount of $4 \mathrm{~mm}$, namely have a thickness of $15 \mathrm{~mm}$. The partial wear pad has a uniform wear amount of $4 \mathrm{~mm}$ and a tangential partial wear amount of $1.5 \mathrm{~mm}$. Tangential partial wear pad shown in Fig.2, the in-friction zone has the maximum amount of partial wear.

\subsection{Finite element model}

In order to ensure that the model can accurately simulate the real friction interface contact pressure distribution under the emergency braking condition and ignoring minor details to simplify the model, the modeling of this paper is based on the following assumptions: (1) The materials of components are uniformly distributed and isotropic. (2) The material of brake disc is HT250.It is a linear material and its material properties do not change with temperature. The material of pad is a resinreinforced composite material, which is a non-linear material. The elastic modulus and thermal expansion coefficient change with temperature. (3) There is elastic contact between brake disc and pad. (4) Consider only thermal conduction and convection, ignoring thermal radiation. (5) Discard brake disc wear during simulation analysis.

Because this paper mainly analyzes the brake friction phenomenon between brake disc and pad, the structural components such as the caliper body and the hub connecting part which have little relation with the research are not considered in the modeling. In order to obtain better convergence of analysis and calculation, remove the ventilation slots and bolt holes in brake disc, but also remove chip straight flute in the middle of pad. Moreover, the shape of pad is also properly simplified to a regular shape. Finally, a simplified finite element model based on ABAQUS software, including brake discs and friction plates, is established as shown in Fig.3. Model is composed of 5950 hexahedron thermal-mechanical coupling units.

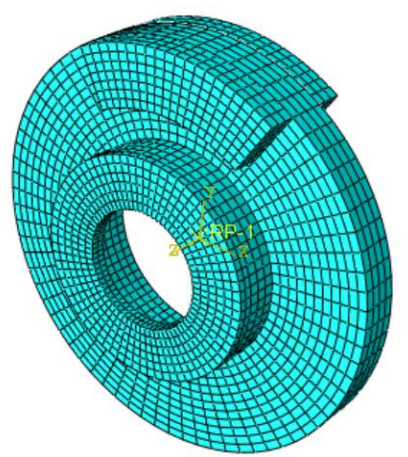

Figure 3. Finite element model of brake disc-pad.

\subsection{The relevant settings of simulation}

(1) Contact relation definition: Contact between brake disc and pads.

(2) The boundary conditions are set as follows: the pressure of brake oil is $8 \mathrm{MPa}$, which is converted to a uniform brake pressure of $3.36 \mathrm{MPa}$ applied to the upper surfaces of pads; Constrained $\mathrm{X}$ and $\mathrm{Y}$ translational degrees of freedom of pad as well as $Z$ rotation degree of freedom of pad; Define a reference point somewhere in the axis of rotation to control the movement of brake disc. The initial angular velocity is $80 \mathrm{rad} / \mathrm{s}$ and the corresponding initial braking speed is $72 \mathrm{~km} / \mathrm{h}$. Brake disc slow down for uniform deceleration. The duration of the entire emergency braking process is $2 \mathrm{~s}$; The convection heat exchange coefficient between pad and surrounding environment and the convective heat dissipation coefficient between brake disc and surrounding environment are known from the literature ${ }^{[8]}$.

(3) Analysis step settings: Simulation is divided into two analysis steps. The first analysis step takes $1 \mathrm{~s}$, applying a uniform brake pressure slowly to pad to improve the convergence of the model calculation. The second analysis step introduces the rotation of brake rotor and it takes $2 \mathrm{~s}$.

(4) Parameter definition: The material properties of each part in the simulation model are shown in Tab.1 and Tab.2. The influences of temperature on the material properties and the friction coefficient of the composite material can be seen in Tab.3 and Tab.4. 
Table 1. Material properties of HT250 (brake disc)

\begin{tabular}{|c|c|c|}
\hline $\begin{array}{c}\text { Density } \\
(\mathrm{kg} / \mathrm{m} 3)\end{array}$ & $\begin{array}{c}\text { Young's modulus } \\
(\mathrm{Pa})\end{array}$ & $\begin{array}{c}\text { Thermal } \\
\text { conductivity } \\
\left(\mathrm{W} \cdot\left(\mathrm{m} \cdot{ }^{\circ} \mathrm{C}\right)-1\right)\end{array}$ \\
\hline 7220 & $1.05 \mathrm{E} 11$ & 48 \\
\hline Poisson's ratio & $\begin{array}{c}\text { Thermal expansion } \\
\left({ }^{\circ} \mathrm{C}-1\right)\end{array}$ & $\begin{array}{c}\text { Specific heat } \\
\left(\mathrm{J} \bullet\left(\mathrm{kg} \cdot{ }^{\circ} \mathrm{C}\right)-1\right)\end{array}$ \\
\hline 0.3 & $4.39 \mathrm{E}-6$ & 419 \\
\hline
\end{tabular}

Table 2. Properties of composites material (pad)

\begin{tabular}{|c|c|}
\hline $\begin{array}{c}\text { Density } \\
(\mathrm{kg} / \mathrm{m} 3)\end{array}$ & $\begin{array}{c}\text { Thermal conductivity } \\
\left(\mathrm{W} \cdot\left(\mathrm{m} \bullet{ }^{\circ} \mathrm{C}\right)-1\right)\end{array}$ \\
\hline 1550 & 0.9 \\
\hline Poisson's ratio & $\begin{array}{c}\text { Specific heat } \\
\left(\mathrm{J} \bullet\left(\mathrm{kg} \cdot{ }^{\circ} \mathrm{C}\right)-1\right)\end{array}$ \\
\hline 0.25 & 1200 \\
\hline
\end{tabular}

Table 3. Effect of temperature on composites material properties

\begin{tabular}{|c|c|c|c|c|}
\hline $\begin{array}{c}\text { Temperature } \\
\left({ }^{\circ} \mathrm{C}\right)\end{array}$ & 20 & 100 & 200 & 300 \\
\hline $\begin{array}{c}\text { Young's modulus } \\
(\mathrm{Pa})\end{array}$ & $2.2 \mathrm{E} 9$ & $1.3 \mathrm{E} 9$ & $5.3 \mathrm{E} 8$ & $3.2 \mathrm{E} 8$ \\
\hline $\begin{array}{c}\text { Thermal expansion } \\
\left({ }^{\circ} \mathrm{C}-1\right)\end{array}$ & $1 \mathrm{E}-5$ & & $3 \mathrm{E}-5$ & \\
\hline
\end{tabular}

Table 4. Effect of temperature on friction coefficient

\begin{tabular}{|c|c|c|c|c|c|}
\hline $\begin{array}{c}\text { Temperature } \\
\left({ }^{\circ} \mathrm{C}\right)\end{array}$ & 20 & 100 & 200 & 300 & 400 \\
\hline Friction coefficient & 0.37 & 0.38 & 0.41 & 0.39 & 0.24 \\
\hline
\end{tabular}

\section{Contact pressure analysis of pads}

Since a pairs of pads are symmetrically arranged with respect to the brake disc, only one pad needs to be analyzed. The pad studied in this paper is the inner pad (near the piston side).

The finite element simulation of the braking process was performed to obtain the contact pressure distribution of new pad at different times, as shown in Fig.4. In order to more intuitively observe the contact pressure changes of new pad during braking process, the contact pressure values of 10 points as shown in Fig. 5 are extracted. The contact pressure curves at circumferential and radial points of new pad were obtained as showed in Fig. 6.

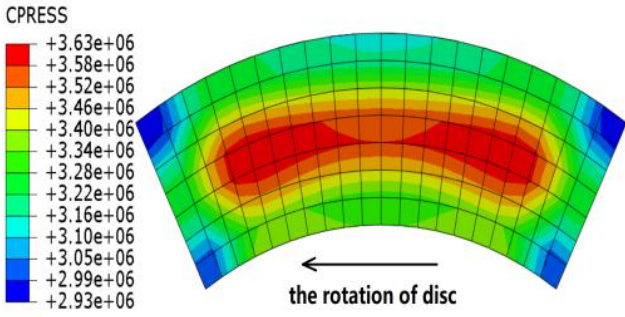

(a) $\mathrm{t}=0 \mathrm{~s}$

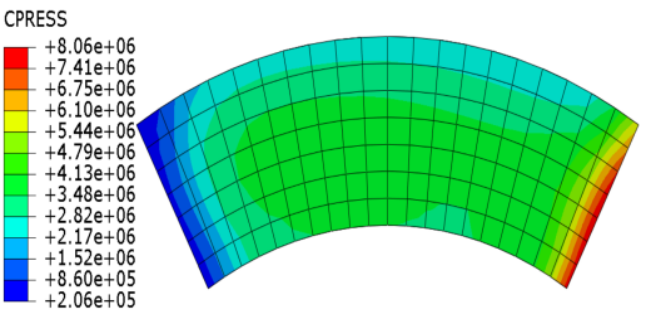

(b) $\mathrm{t}=0.05 \mathrm{~s}$

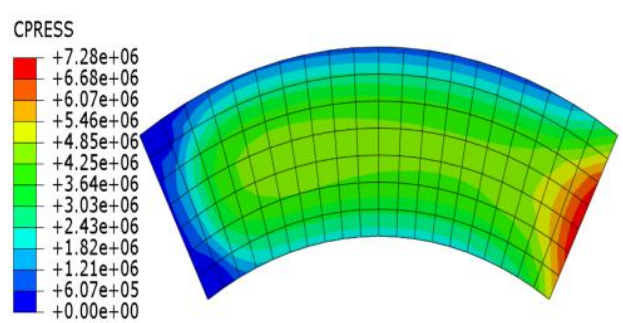

(c) $\mathrm{t}=1 \mathrm{~s}$

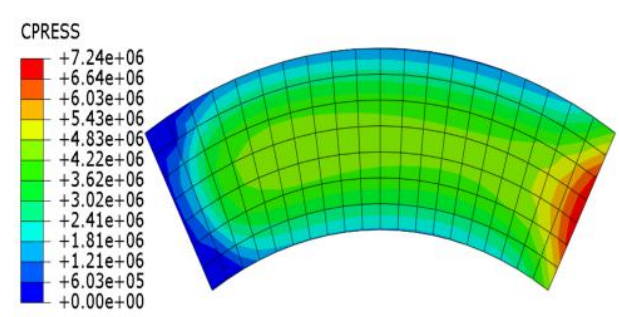

(d) $\mathrm{t}=2 \mathrm{~s}$

Figure 4.Contact pressure distribution of new pad at different times.

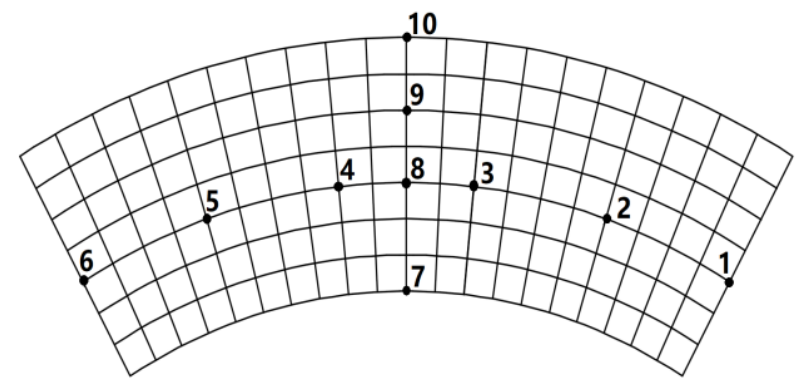

Figure 5. Distribution of measuring points on pad. 


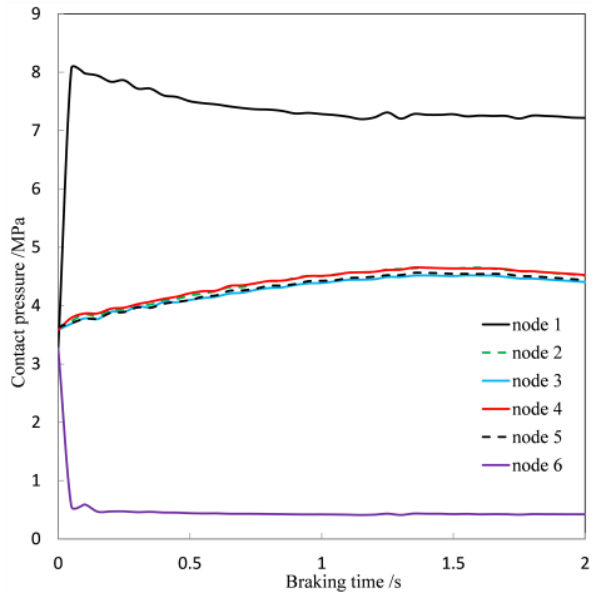

(a) Circumferential

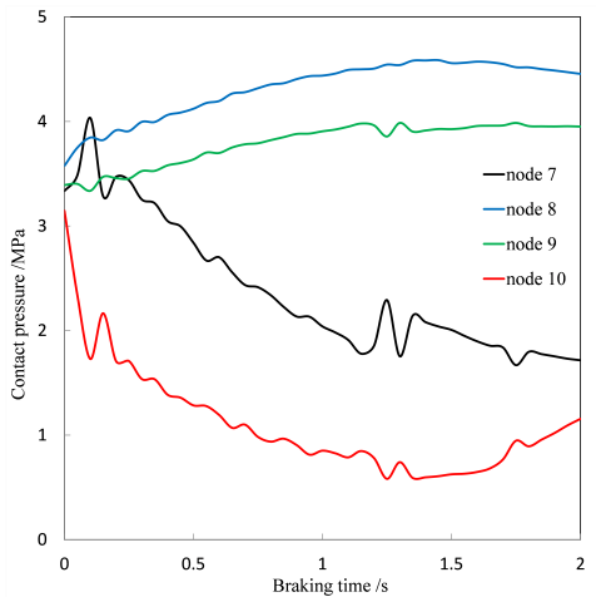

(b) Radial

Figure 6. Contact pressure curves of each point on new pad.

\subsection{Contact pressure distribution of new pad}

Static (brake disc has not yet rotated) contact pressure distribution of new pad can be seen from Fig.4 (a). It can be seen that when the friction force is not considered, the contact stress distribution of new pad is not uniform. Distribution trend is that the middle is bigger than the around, and the maximum pressure appears in the middle of pad with a value of $3.63 \mathrm{MPa}$. This uneven distribution of contact pressure is caused by the elastic deformation of brake disc and pad.

As can be seen from Fig.4 and Fig.6 (a): (1) When brake disc just started to rotate, the contact pressure distribution of new pad changed obviously under the combined influences of positive braking force and friction force. The circumferential distribution more uneven, the maximum contact pressure appears in the infriction zone, and its value increased from $3.63 \mathrm{MPa}$ to $8 \mathrm{MPa}$. The minimum contact pressure appears in the outfriction zone with a value of $0.2 \mathrm{MPa}$. The contact pressure of the central part did not change much, has been slowly increasing. (2) The contact pressure in the central part of new pad is almost equal.

\subsection{Effect of wear amount and partial wear on contact pressure of pad}

The contact pressure values of six nodes in the wear pad and partial wear pad were extracted. The contact pressure curve is shown in Fig.7. Comparing Fig.6 (a) and Fig.7, we can see that the trend of the contact pressure curve of new pad, wear pad and partial wear pad is the same, but the values is quite different. Since the contact pressures of the four nodes in the middle are almost the same, the contact pressure curves of the nodes 1,4 , and 6 on the three pads are compared to obtain Fig. 8.

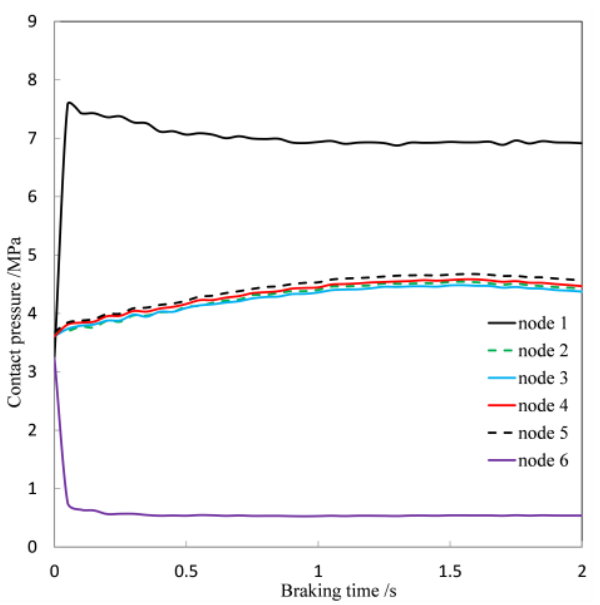

(a) wear pad

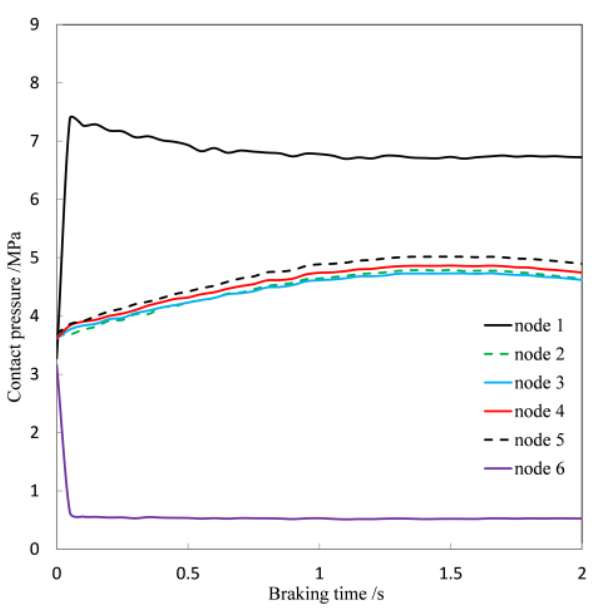

(b) partial wear pad

Figure 7. Contact pressure curves of circumferential points on wear pad and partial wear pad.

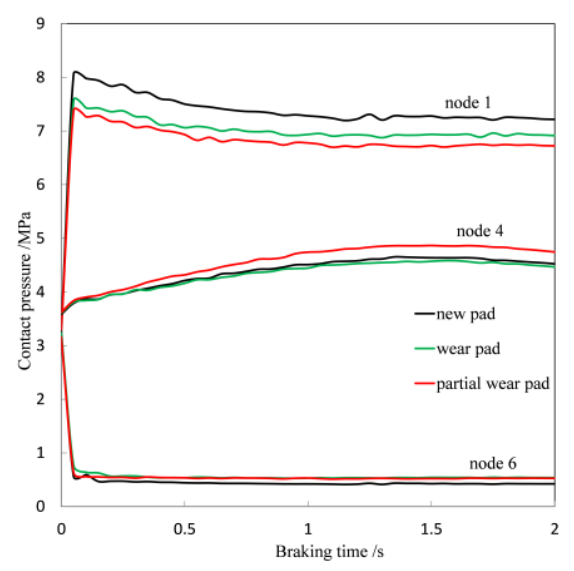

Figure 8. Contact pressure curves of node1, 4, 6 on different pad. 
From Fig. 8 we can see: In the in-friction zone (the area with the highest contact pressure), the contact pressure of partial wear pad is obviously lower than that of the new pad and wear pad. In the middle part and the out-friction zone, the contact pressure of partial wear pad is obviously higher than the latter two, namely the contact pressure distribution of partial wear pad is more even. The above shows that wear amount has little effect on the contact pressure distribution of pad, while partial wear has significant effect on the contact pressure distribution of pad.

\section{Force characteristics and wear characteristics of pad}

By analyzing the force characteristics of pad in different stages, the wear characteristics of pad over the whole life cycle are explored.

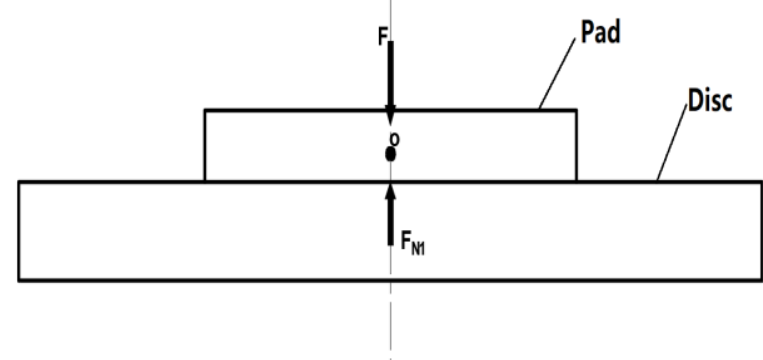

(a) New pad

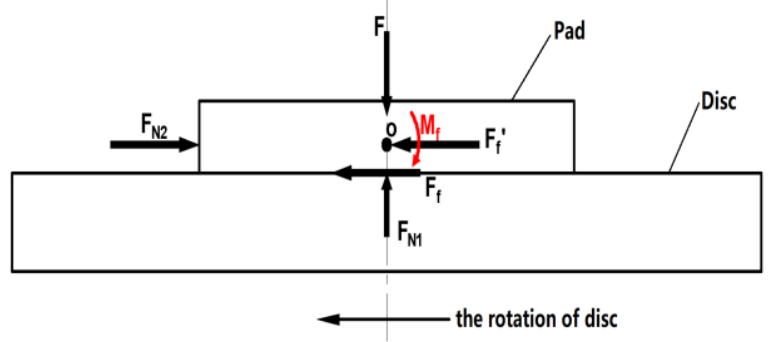

(b) Prophase

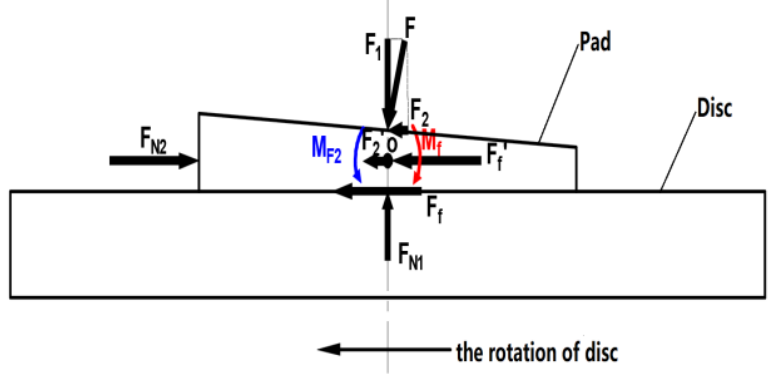

(c) In the late

Figure 9. Force analysis of pad at different Stages.

Fig. 9 (a) shows the force characteristics of new pad when it is not working, meanwhile the brake disc has not been rotated yet. Brake pressure $\mathrm{F}$ makes pad and brake disc pressed tightly, then brake disc produce a reverse support force FN1 on pad, so that the forces on pad are balanced in the vertical direction.
Fig. 9 (b) shows the force characteristics of pad in its prophase of life cycle, meanwhile brake disc began to rotate and wear has not been produced yet. So that friction force $\mathrm{Ff}$ is generated on the friction interface, which is equivalent to the force $\mathrm{Ff}^{\prime}$ and the moment $\mathrm{Mf}$ on the center of mass of pad. And the support force FN2 of carrier to pad makes the forces balance in the horizontal direction. Therefore, the only moment Mf will make pad rotate around its center of mass, resulting in the in-friction zone compact and the out-friction zone relax. This is consistent with the contact pressure distribution of new pad in the previous section, which verifies the correctness of the simulation.

According to Archard's law of wear [9] [10]:

$$
\Delta h=k_{d} p_{c} \Delta S
$$

where $\Delta h$ is the depth of wear in time $\Delta t, \Delta S$ is the sliding displacement of brake disc relative to pad, $k_{d}$ is a constant, and $p_{c}$ is the contact pressure at each point on the contact interface of pad.

According to equation (1) shows that the wear of pad is directly related to the contact pressure. Therefore, according to the contact pressure distribution of new pad, it can be seen that new pad begins partial wearing in the early stage.

Fig. 9 (c) shows the force characteristics of pad after partial wear. At this time, the brake pressure $\mathrm{F}$ is still perpendicular to the upper surface of pad but at an angle to the vertical. F1 and F2 are the horizontal and vertical components of the force $\mathrm{F}$ respectively. F2 is equivalent to the center of mass of pad, and obtain the force F2' and the torque MF2. The direction of MF2 is the opposite of Mf. When the amount of partial wear reaches a certain amount, the two moments are equal size and offset each other. Then the contact pressure of pad tends to be uniform, the wear of pad tends to be uniform. This is consistent with the more even contact pressure distribution of partial wear pad in the previous section, and verifies the correctness of the simulation again.

The above analysis shows that due to the friction moment $\mathrm{Mf}$, the contact pressure distribution of new pad is uneven, resulting in tangential partial wear. As the amount of partial wear increases, the moment MF2 generated by the horizontal component of brake pressure gradually increases, then the contact pressure of pad becomes more and more uniform. When these two moments are equal in size, the contact pressure of pad tends to be uniform and the amount of wear tends to be uniform, then the pad has been uniformly worn since then.

\section{Conclusion}

(1) During the whole braking process, the temperature distribution and the contact pressure distribution of new pad are not uniform, and the maximum contact pressure appears in the in-friction zone. The contact pressure of each point on pad varies and the contact pressure at each point in the middle part keeps rising slowly. In addition, the contact pressure distribution of pad has changed a lot 
when brake disc is rotated, which shows that the friction force is the crucial factor that affects the contact pressure distribution of pad, but the temperature and thermal stress are the very small factor.

(2) By comparing the contact pressure distribution of wear pad, tangential partial wear pad and new pad, we can see that: the wear amount had little effect on the contact pressure of pad, while the tangential partial wear had a great influence on the contact pressure of pad.

(3) The force and wear characteristics of pad are analyzed. The wear of life cycle of pad is obtained, and the reliability and accuracy of the simulation are verified. The wear of new pad is tangential partial wear in the early stage, and the wear tends to be uniform when the amount of partial wear reaches a certain moment. Namely, the pad wear has an adaptive adjustment process. In general, the tangential partial wear of pad is difficult to avoid, but the amount of partial wear can be controlled in a small range.

\section{References}

1. Ouyang Huajiang. A combined analysis of heat conduction, contact pressure and transient vibration of a disk brake [J]. Drive System Technique, 2003; 51.1/2: 190-206
2. Zhao Bo, Fan Pingqing. Analyzing in braking efficiency and contact stress of disc brake [J]. Machinery Design \& Manufacture, 2011(9): 134-136

3. Huang Jianmeng, Gao Chenghui, Lin Xiezhao, et al. Study on the contact pressure distribution of a disc brake $[\mathrm{J}]$. Chinese Journal of Solid Mechanics, 2007, 28 (3): 297-302

4. Zhang Lijun, Chen Yuan, Diao Kun, et al. Computational investigation into disc-pads pressure distribution and thermo-mechanical coupling characteristics of brake pads in disc brake [J]. Journal of Tongji University(Natural Science), 2013, 41(10): 1554-1561

5. Söderberg A, Andersson S. Simulation of wear and contact pressure distribution at the pad-to-rotor interface in a disc brake using general purpose finite element analysis software[J]. Wear, 2009, 267(12): 2243-2251

6. Gao Hongxiang, Wang Xiaofei. Research of pressure distribution state of disc brake [J]. Journal of Mechanical Transmission, 2014(9): 39-42

7. Bakar A R A, Ouyang H, Siegel J E. Brake pad surface topography part I: contact pressure distribution [J]. Automotive Sector, 2005

8. Zhao Tenglun. ABAQUS 6.6 application in mechanical engineering $[\mathrm{M}]$. China Water \& Power Press, 2007. 